\title{
Moderate- to low-risk variant alleles of cutaneous malignancies and nevi: lessons from genome-wide association studies
}

\author{
Durga Udayakumar and Hensin Tsao*tł
}

\begin{abstract}
Addresses: *Department of Dermatology, Wellman Center for Photomedicine, 48 Blossom Street, Massachusetts General Hospital, Boston, MA 02114, USA. †Harvard Medical School, 25 Shattuck Street, Boston, MA 02115, USA. ¥MGH Melanoma and Pigmented Lesion Center/ MGH Cancer Center, 50 Staniford Street, Suite 200, Boston, MA 02114, USA.
\end{abstract}

Correspondence: Hensin Tsao. Email: htsao@partners.org

\begin{abstract}
Cutaneous malignancies, especially malignant melanoma, exhibit great genetic heterogeneity. As a result, some individuals and families have particularly increased risk due to genetic predisposition to the disease. The susceptibility alleles range from rarely occurring, heritable, high-risk variants to ubiquitously occurring low-risk variants. Although until now the focus has been mostly towards the familial high-risk genes, the development of genome-wide association studies has uncovered a number of moderate- to low-risk predisposition alleles. The ability to specifically identify genetic variation associated with visible pigmentation traits and disease risk has provided a much richer view of the genetics of cutaneous malignancies. In this review, we provide an update on the recently identified risk loci. Existing clinical data, combined with vast genome information, will provide a better understanding of the biology of disease, and increased accuracy in risk prediction.
\end{abstract}

\section{Introduction}

Cutaneous malignancies such as highly invasive melanoma, and the keratinocyte carcinomas, such as basal cell carcinoma (BCC) and squamous cell carcinoma (SCC), have become increasingly common in recent decades. According to the Surveillance, Epidemiology and End Results (SEER) program, it is estimated that 74,610 men and women will be diagnosed with skin cancer in 2009 in the United States, and mortality is estimated to be 11,590 (excluding BCC and SCC) [1]. For melanoma alone, the diagnosis is estimated to be 68,720 , and 8,650 [2]. BCC is the most common type of skin cancer and accounts for $80 \%$ of all skin cancers. Nearly half of people with $\mathrm{BCC}$ have recurrent tumors within five years of development of the primary tumor.

Like most cancers, the risk factors for cutaneous malignancies include both genetic and environmental components. The notion that melanoma has a genetic predisposition was first put forth in 1820 by William Norris, who claimed it has 'a strong tendency to hereditary predisposition' [3]. Later studies reported correlation between the prevalence of familial multiple melanomas and the occurrence of 'atypical nevi (moles)', and they were described as familial atypical multiple-mole melanoma (FAMMM) syndrome or BK mole syndrome [4,5]. Advances in linkage analysis in the late 1980 s to early 1990 directed much attention towards identifying highrisk, high-penetrance loci associated with familial predisposition to melanoma. Several groups identified germline mutations of the p16INK4a (now cyclin-dependent kinase inhibitor 2A, CDKN2A) gene on chromosome 9p21, and established the molecular basis of hereditary melanoma in a subset of melanoma-prone kindreds (highlighted in [6]). Subsequently, Zuo and colleagues [7] identified heritable alterations in the $C D K 4$ gene in a few families that lacked germline $C D K N 2 A$ mutations. The mutation rates of high-risk heritable alleles are less prevalent, although the biological relevance of these mutations is well characterized (reviewed in [8-10]). A study in three continents including a large population demonstrated that mutations in $C D K N_{2} A$ loci account for disease susceptibility in 20 to $57 \%$ of all melanoma families [11].

With the completion of the Human Genome Project and the HapMap and the recognition that single nucleotide polymorphisms (SNPs) are found in the genome at fixed locations, it became feasible to perform large-scale genome-wide association studies (GWAS) in order to systematically search for other low- to moderate-riskconferring alleles that could contribute to sporadic cutaneous melanoma (CM). In this review, we provide an

ASIP, Agouti signal protein; BCC, basal cell carcinoma; CDKN2A/B, cyclin-dependent kinase inhibitor 2A/B; Cl, confidence interval; CM, cutaneous melanoma; CN, cutaneous nevi; FAMM, familial atypical multiple-mole melanoma; GWAS, genome-wide association study; KITLG, KIT ligand; KRT5, keratin 5; MC1R, melanocortin-1-receptor; MSH, melanocortin-stimulating hormone; MTAP, methylthioadenosine phosphorylase; NBCSS, nevoid basal cell carcinoma syndrome; OCA2, oculocutaneous albinism II; OR, odds ratio; RHC, red hair color; SCC, squamous cell carcinoma; SEER, Surveillance, Epidemiology and End Results; SLC24A4, solute carrier family 24; SNP, single nucleotide polymorphism; TERT-CLPTM1L, telomerase reverse transcriptase-cleft lip and transmembrane 1-like; TPCN2, two-pore segment channel 2; TYR, tyrosinase; TYRP1, tyrosinase-related protein 1; UVR, ultraviolet radiation. 
update on newly identified genetic variants associated with melanoma risk, pigmentation phenotypes such as skin color, hair color and sun sensitivity, and development of cutaneous nevi $(\mathrm{CN})$ count. A recent article examining BCC is also considered, since susceptibility to melanoma may also result in high-risk predisposition to other such forms of cutaneous malignancies [12]

\section{Risk variants of cutaneous malignancies Association with pigmentation phenotype and risk of cutaneous melanoma}

A comprehensive meta-analysis by Gandini and colleagues [13] revealed a direct link between pigmentation and melanoma risk. There are more than 120 genes involved in regulating pigmentation status, among which melanocortin-1-receptor $(M C 1 R)$ is a key regulator. Many variants of this gene sequence are implicated in melanoma risk (reviewed in [14,15]). MC1R triggers a cAMP-dependent intracellular response that leads to the production of dark eumelanin in preference over red pheomelanin (Figure 1); eumelanin is thought to provide greater protection against ultraviolet radiation (UVR) than pheomelanin $[16,17]$. The presence of germline $M C 1 R$ variants correlates with skin/ hair color and poor tanning ability (80\% in individuals with red hair color (RHC) and/or fair skin, 20\% in individuals with brown or black hair, and less than $4 \%$ in people with good tanning response) and increases $\mathrm{CM}$ risk by 3.9-fold [18]. Raimondi and colleagues [19] reviewed all $M C 1 R$ variants and classified them based on RHC phenotype: (a) four ' $\mathrm{R}$ ' $M C 1 R$ variants (p.Asp84Glu, p.Arg151Cys, p.Arg16oTrp, and p.Asp294His) strongly associated with the RHC phenotype; (b) two less frequent ' $R$ ' alleles ( $p$. Arg142His and p.Ile155Thr) based on strong familial association with RHC phenotype; and (c) three ' $r$ ' alleles (p.Val6oLeu, p.Val92Met, and p.Arg163Gln) with weaker association with the RHC phenotype. Except for p. Val6oLeu and p.Val92Met, all other variants appear significantly associated with melanoma risk, with odds ratios (ORs) with a 95\% confidence interval (CI) ranging from 1.42 (1.09 to 1.85) for p.Arg163Gln to 2.45 (1.32 to 4.55) for p.Ile155Thr. Two studies estimated the penetrance of $M C 1 R$ variants to be approximately $84 \%$ $[20,21]$. There is also some early evidence that $M C 1 R$ status is associated with $B R A F$ mutagenesis, suggesting a predisposition to develop $B R A F$-driven tumors in individuals carrying these variants [22,23].

Another GWAS identified variants associated with hair and eye pigmentation, skin sensitivity to sun and freckling among 2,986 Icelanders [24]. Shortly thereafter, the same group discovered another two coding variants in TPCN2 (two-pore segment channel 2) that were associated with hair color, and a variant at the ASIP locus (which encodes the Agouti protein) that showed strong association with sun sensitivity, freckling, and red hair - phenotypic features similar to those in individuals carrying variants in
$M C 1 R$ [25]. In 2008, a much larger study examined 11 SNPs from eight pigmentation-associated loci (SLC24A4 (solute carrier family 24), KITLG (KIT ligand), 6p25.3, TYR (tyrosinase), OCA2 (oculocutaneous albinism II), TPCN2 (two-pore segment channel 2), ASIP (Agouti signal protein), TYRP1 (tyrosinase-related protein 1)) for CM and BCC risk. Three cohorts (810 individuals with $\mathrm{CM}$ and 36,723 non-CM controls from Iceland; $1,033 \mathrm{CM}$ cases and 2,650 controls from Sweden and $278 \mathrm{CM}$ cases and 1,297 controls from Spain) were tested for melanoma risk effects. A two-SNP haplotype was identified at the ASIP locus that showed strong association with $\mathrm{CM}$ (combined $\mathrm{OR}=1.45$; $P=1.2 \times 10^{-9}$ ), while an additional non-synonymous coding variant in TYR (combined OR $=1.21 ; P=2.8 \times 10^{-7}$ ) and a non-coding SNP at the TYRP1 locus were also associated significantly with melanoma risk (rs1408799; combined for all three samples, $\mathrm{OR}=1.15 ; P=0.00043$ ) [26]. A second independent GWAS based in Australia also found evidence of a melanoma risk locus at the ASIP locus on chromosome 20q11 [27].

A recent GWAS based on population samples collected across European populations living at different latitudes has uncovered additional melanoma risk loci with suggestive biological consequences [28], although these are yet to be validated. The result was a joint effort from ten GenoMEL groups with 1,650 cases and 1,065 controls. The team identified five loci on chromosomes 2, 5, 9, 11 and 16 , with at least one SNP at each locus with genomewide significance $\left(P<5 \times 10^{-7}\right)$. Three of these loci were replicated in an independent cohort of 1,163 cases and 903 controls. The strongest association was seen in chromosome 16q, with one new SNP (rs8059973, OR = 0.74), which was different from two other previously reported SNPs on the same locus with association to hair color and skin pigmentation (rs258322, rs4785763) [29]. The $\operatorname{rs} 8258322 \mathrm{SNP}\left(\mathrm{OR}(95 \% \mathrm{CI})=1.16 \times 10^{-12}\right.$ to $\left.2.54 \times 10^{-27}\right)$ was comparable to the $M C 1 R$ variant previously described [21] in terms of increased cutaneous melanoma risk, though the location of the SNP is distant from the $M C 1 R$ locus per se. In addition, a chromosome 11 SNP near the $T Y R$ gene showed evidence of association with melanoma (rs1393350; $P=2.41 \times 10^{-4}$ ). A third region on chromosome 9p21 also showed significant association with melanoma. The implicated SNP (rs7023329, $P=4.03 \times 10^{-7}$ ) is near, but distinct from, the high-risk CDKN2A locus; it appears to be more physically aligned with the methylthioadenosine phosphorylase (MTAP) gene that flanks the CDKN2A region. These novel loci will be a key addition to the pigmentation variants of TYR previously identified by deCODE genetics [26].

The GWAS analyses also uncovered some risk variants whose genetic interactions are more complex. Interestingly, in the large Icelandic-based GWAS, $M C 1 R$ variants conferred little or no increased risk of $\mathrm{CM}$ among the 


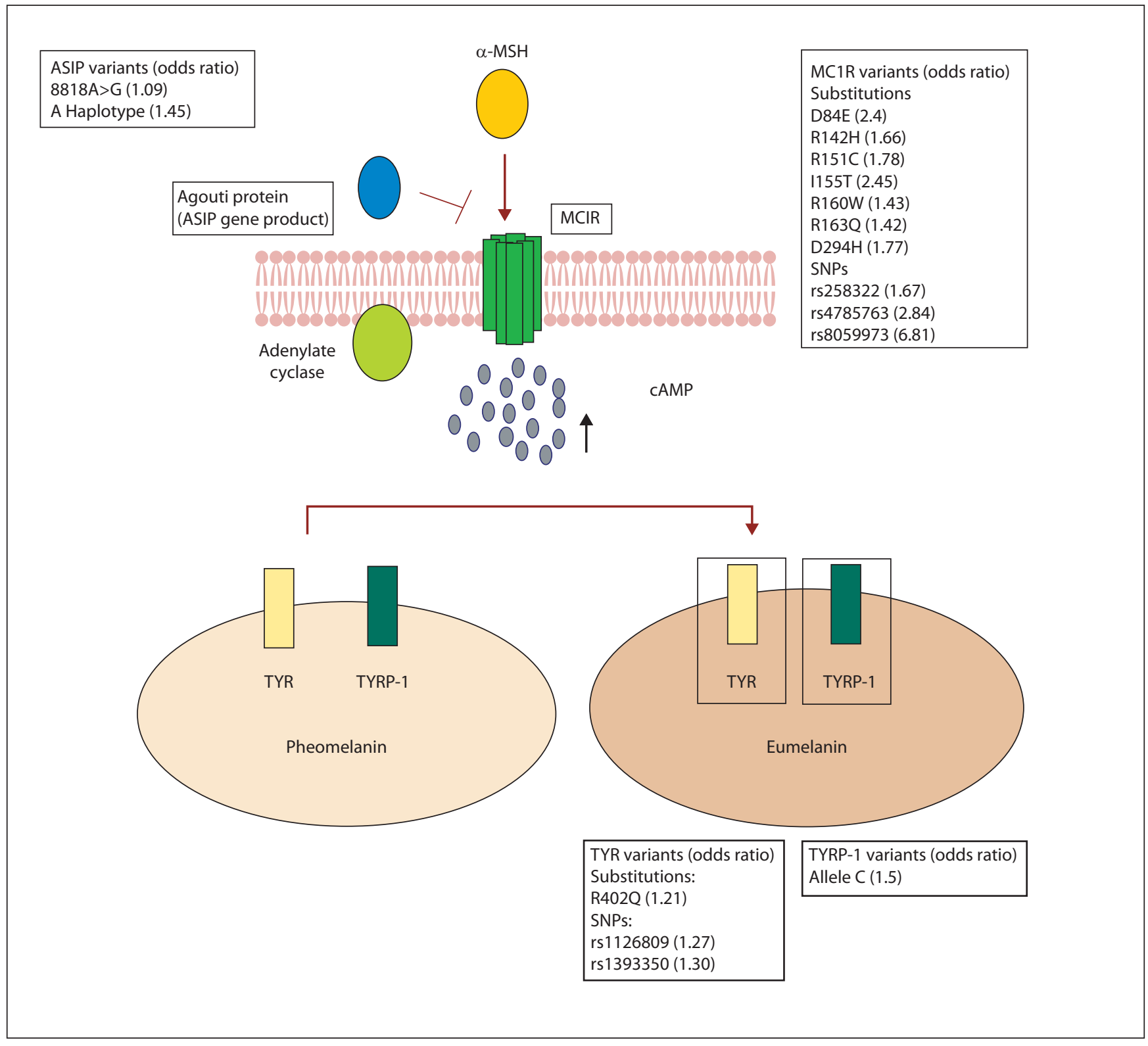

Figure 1

An illustration of the MC1R pigmentation pathway and the loci implicated in melanoma risk. The binding of melanocortin-stimulating hormone $(\alpha-M S H)$ to its transmembrane receptor, Melanocortin-1-receptor (MC1R), results in stimulation of adenylate cyclase (AC) to produce cAMP. An antagonist to $\alpha-M S H$, called Agouti protein (encoded by ASIP loci), inhibits this interaction. The release of cAMP in the cytoplasm activates the melanosomal enzymes, including tyrosinase (TYR) and tyrosinase-related protein-1 (TYRP-1), on the cell membrane of the melanosomes, resulting in a shift of pigment synthesis from pheomelanin to eumelanin. The variants of the genes encoding these proteins are listed. The corresponding odds ratio represents the risk of developing melanoma in patients carrying these variants.

Icelandic population, whereas significant risks for CM were observed in both the Swedish and Spanish cohorts [25]. These findings suggest that RHC variants are not the only genetic risk factors for melanoma in the Icelandic cohort. This is consistent with an earlier study showing that some $M C 1 R$ variants conferred melanoma risk but were not associated with hair and skin color phenotypes [21]. Table 1 summarizes the known relationships between various GWAS loci and their associated pigmentary and cancer phenotypes.

\section{Variants associated with risk of basal cell carcinoma}

$\mathrm{BCC}$ is the most common cancer and is sporadic in nature, although inherited forms have been described in the case 
Table 1

\begin{tabular}{lll}
\multicolumn{4}{l}{ GWAS loci and the associated pigmentary and cancer phenotypes } & \\
\hline Chromosomal region/locus (SNP region) [Reference] & Pigmentation status & Cancer phenotype \\
\hline MC1R (RHC, NRHC) multiple SNPs [18,19,28] & Blonde/red hair, freckling & Skin sensitivity, CM, BCC \\
TYR (rs1126809, rs1042602, rs1393350) [24,26,28,29] & Blue versus green eyes, freckling & Skin sensitivity, CM, BCC \\
TYRP1 (rs1408799) [25,26] & Blonde hair (weak), brown eyes, green eyes (weak) & CM \\
ASIP haplotype (rs1015362[G], rs4911414[T]) [25,26] & Red and blonde hair, Freckling & CM, BCC, skin sensitivity \\
TPCN2 (rs35264875[T], rs3829241[A]) [25] & Blonde hair versus brown & CM and BCC (weak) \\
SLC24A4 (rs12896399) [24] & Blonde hair, green eyes brown eyes (weak) & Skin sensitivity (weak) \\
KITLG (rs12821256) [24] & Blonde hair & Not known \\
6p25.3 (rs1540771) [24] & Blonde hair, freckling & Skin sensitivity (weak) \\
OCA2 (rs1667394, rs7495174) [24] & Blonde hair, green and brown eyes & Skin sensitivity (weak) \\
$9 p 21$ adjacent to MTAP (rs7023329) [28] & Blonde hair, green and brown eyes, freckling & Skin sensitivity, CM \\
$9 p 21$ adjacent to CDKN2A/B [12] & No association & BCC, no association to CM \\
KRT5, G138E substitution [12] & No association & BCC, no association to CM \\
7q32 adjacent to KLF14 [12] & No association & BCC, no association to CM \\
MTAP rs4636294 ref [37] & Not known & Not known \\
PLA2G6 (rs2284063) [37] & CM
\end{tabular}

$\mathrm{BCC}$, basal cell carcinoma; $\mathrm{CM}$, cutaneous melanoma; $\mathrm{NRHC}$, non-red hair color variants; $\mathrm{RHC}$, red hair color variants.

of nevoid basal cell carcinoma syndrome (NBCCS). This is characterized by rapid development of numerous BCCs in young patients, with a median age of 20 years [30,31]. Susceptibility to BCC has been shown to be strongly associated with variants on chromosomes 1p36, 1q42, and 5 p15 [32]. Notably, some of the sequence variants responsible for BCC appear to be independent of pigmentation traits; in fact, the $5 \mathrm{p} 15$ variant at the TERT-CLPTM1L (telomerase reverse transcriptase-cleft lip and palate transmembrane 1-like) locus is protective against melanoma. The deCODE group also identified three SNPs associated with non-melanoma skin cancer but not melanoma or pigmentation: (a) rs11170164 in the keratin $5(K R T 5)$ gene with a G138E substitution (combined OR 1.35, $P=2.1 \times 10^{-9}$ ) conferring susceptibility to BCC; (b) rs2151280 on chromosome 9p21 near the $C D K N 2 A / B$ locus; and (c) rs157935 on chromosome $7 \mathrm{q} 32$ [12].

\section{Risk variants for cutaneous nevi}

Melanocytic nevi (or 'moles') represent both precursors and markers of melanoma risk [33,34]. The genetics of melanocytic nevus formation appear to be related to, but distinct from, CM development. A meta-analysis of 46 different studies related to nevus formation and melanoma risk showed that a high mole count (101 to 120) increased the relative risk (RR) of melanoma by about seven-fold ( $\mathrm{RR}=6.89 ; 95 \% \mathrm{CI})$ when compared to a low nevus count (o to 15). In a parallel estimate, the RR was over six times higher between the presence of five atypical moles and no moles at all ( $\mathrm{RR}=6.52 ; 95 \% \mathrm{CI})$ [33]. These studies clearly highlight that an increase in nevus count may indicate a genetic predisposition to melanoma but that environmental factors such as UV exposure and the deregulation of genes at particular signaling pathways could potentiate this effect. Subsequent studies have linked a high nevus count to the two melanoma loci on chromosome 9 including the CDKN2A region [35,36]. Recently, a large GWAS was conducted on mole count using 297,108 SNPs in a cohort of 1,524 twins from the TwinsUK registry, with subsequent validation in an independent European cohort. The strongest association was reported for a SNP in the MTAP locus next to $C D K N 2 A$ on chromosome 9p21 (rs4636294, combined $P=3.4 \times 10^{-15}$ ). Another SNP on 22q13.1 $(\mathrm{rs132985}, \mathrm{OR}=1.23)$ also showed a strong replicated signal $\left(P=2.6 \times 10^{-7}\right)[37]$. It is intriguing to note that $9 \mathrm{p} 21$ loci also harbor SNPs that have been implicated in both susceptibility to BCC and association to pigmentation phenotypes as described above $[12,28]$. The associated SNP on chromosome 9p21, rs 7023329, which was reported in the Bishop et al. study [28], has also been reported in this study. Furthermore, the 9p21 locus also harbors strong-risk SNPs for cardiac disease and type II diabetes. The biological relationship between these SNPs and different disorders remains a source of intense investigation.

\section{Summary}

Large-scale GWASs have identified a large number of moderate- to low-risk melanoma variants in different cohorts over the past few years. The information gained 
from these studies advances melanoma risk prediction more than ever. Although interesting in its own right, the GWAS results are unlikely to impact clinical management at the current time. Lower-risk alleles compete against other behavioral risk factors that may modulate one's overall likelihood of developing melanoma and other forms of skin cancer. It is also somewhat ironic that high-power genetic approaches have recovered strong allelic signals in pathways that dictate pigmentation - a phenotype well known for decades to confer cancer risk. The recent harvest of GWAS analyses provides a fundamental element for risk prediction but further research is needed. Commercial interest in utilizing GWAS results should be viewed with some trepidation, as it may lead to a false sense of security, or anxiety. However, the promise of this new information is a clearer explanation of gene-gene and gene-environment interactions that will undoubtedly emerge over the next decade.

\section{Competing interests}

The authors declare that they have no competing interests.

\section{Authors' contributions}

DU and HT wrote the manuscript. Both authors approved the final version of the manuscript.

\section{Acknowledgements}

The authors would like to thank all the colleagues around the world whose scientific contributions formed the basis of this article.

\section{References}

1. SEER Database [http://seer.cancer.gov/statfacts/html/skin. html]

2. Jemal A, Siegel R, Ward E, Hao Y, Xu J,Thun MJ: Cancer statistics, 2009. CA Cancer J Clin 2009, 59:225-249.

3. Roderick McLeod G, Davis NC, Sober AJ: A history of melanoma: From Hunter to Clark. In Cutaneous Melanoma. 4th edition. Edited by Balch CM, Houghton AN, Sober AJ, Soong S-j. St Louis: Quality Medical Publishing, Inc.; 2003:212.

4. Clark WH Jr, Reimer RR, Greene M, Ainsworth AM, Mastrangelo $\mathrm{MJ}$ : Origin of familial malignant melanomas from heritable melanocytic lesions. 'The B-K mole syndrome'. Arch Dermatol 1978, 114:732-738.

5. Lynch HT, Frichot BC 3rd, Lynch JF: Familial atypical multiple mole-melanoma syndrome. J Med Genet 1978, 15:352356.

6. Wainwright B: Familial melanoma and p16 - a hung jury. Nat Genet 1994, 8:3-5.

7. Zuo L, Weger J, Yang Q, Goldstein AM, Tucker MA, Walker GJ, Hayward N, Dracopoli NC: Germline mutations in the p16INK4a binding domain of CDK4 in familial melanoma. Nat Genet 1996, 12:97-99.

8. Udayakumar D, Tsao $\mathrm{H}$ : Melanoma genetics: an update on risk-associated genes. Hematol Oncol Clin North Am 2009, 23:415-429, vii.

9. Bishop JN, Harland M, Bishop DT: The genetics of melanoma. Br J Hosp Med (Lond) 2006, 67:299-304.

10. Chin L, Garraway LA, Fisher DE: Malignant melanoma: genetics and therapeutics in the genomic era. Genes Dev 2006, 20:2149-2182.

11. Goldstein AM, Chan M, Harland M, Hayward NK, Demenais F, Bishop DT, Azizi E, Bergman W, Bianchi-Scarra G, Bruno W,
Calista D, Albright LA, Chaudru V, Chompret A, Cuellar F, Elder DE, Ghiorzo P, Gillanders EM, Gruis NA, Hansson J, Hogg D, Holland EA, Kanetsky PA, Kefford RF, Landi MT, Lang J, Leachman SA, MacKie RM, Magnusson V, Mann GJ, et al:: Features associated with germline CDKN2A mutations: a GenoMEL study of melanoma-prone families from three continents. J Med Genet 2007, 44:99-106.

12. Stacey SN, Sulem P, Masson G, Gudjonsson SA, Thorleifsson $G$, Jakobsdottir $M$, Sigurdsson $A$, Gudbjartsson DF, Sigurgeirsson $\mathrm{B}$, Benediktsdottir KR, Thorisdottir K Ragnarsson R, Scherer D, Hemminki K, Rudnai P, Gurzau E, Koppova K, Botella-Estrada R, Soriano V, Juberias P, Saez B, Gilaberte Y, Fuentelsaz V, Corredera C, Grasa M, Hoiom V, Lindblom A, Bonenkamp JJ, van Rossum MM, Aben KK, et al.: New common variants affecting susceptibility to basal cell carcinoma. Nat Genet 2009, 41:909-914.

13. Gandini S, Sera F, Cattaruzza MS, Pasquini P, Zanetti R, Masini C, Boyle P, Melchi CF: Meta-analysis of risk factors for cutaneous melanoma: III. Family history, actinic damage and phenotypic factors. Eur J Cancer 2005, 41: 2040-2059.

14. Lin J, Hocker TL, Singh M, Tsao H: Genetics of melanoma predisposition. Br J Dermatol 2008, 159:286-291.

15. Rouzaud F, Kadekaro AL, Abdel-Malek ZA, Hearing VJ: MC1R and the response of melanocytes to ultraviolet radiation. Mutat Res 2005, 571:133-152.

16. Garcia-Borron JC, Sanchez-Laorden BL, Jimenez-Cervantes $\mathrm{C}$ : Melanocortin-1 receptor structure and functional regulation. Pigment Cell Res 2005, 18:393-410.

17. Mas JS, Gerritsen I, Hahmann C, Jimenez-Cervantes C, Garcia-Borron JC: Rate limiting factors in melanocortin 1 receptor signalling through the cAMP pathway. Pigment Cell Res 2003, 16:540-547.

18. Valverde P, Healy E, Jackson I, Rees JL,Thody AJ: Variants of the melanocyte-stimulating hormone receptor gene are associated with red hair and fair skin in humans. Nat Genet 1995, 11:328-330.

19. Raimondi S, Sera F, Gandini S, lodice S, Caini S, Maisonneuve P,Fargnoli MC: MC1R variants, melanoma and red hair color phenotype: a meta-analysis. Int J Cancer 2008, 122:27532760.

20. Box NF, Duffy DL, Chen W, Stark M, Martin NG, Sturm RA, Hayward NK: MC1R genotype modifies risk of melanoma in families segregating CDKN2A mutations. Am J Hum Genet 2001, 69:765-773.

21. Kennedy $C$, ter Huurne J, Berkhout M, Gruis N, Bastiaens M, Bergman $\mathrm{W}$, Willemze $\mathrm{R}$, Bavinck $\mathrm{JN}$ : Melanocortin 1 receptor (MC1R) gene variants are associated with an increased risk for cutaneous melanoma which is largely independent of skin type and hair color. J Invest Dermatol 2001, 117:294300.

22. Fargnoli MC, Pike K, Pfeiffer RM, Tsang S, Rozenblum E, Munroe DJ, Golubeva Y, Calista D, Seidenari S, Massi D, Carli P, Bauer J, Elder DE, Bastian BC, Peris K, Landi MT: MC1R variants increase risk of melanomas harboring BRAF mutations. J Invest Dermatol 2008, 128:2485-2490.

23. Landi MT, Bauer J, Pfeiffer RM, Elder DE, Hulley B, Minghetti P, Calista D, Kanetsky PA, Pinkel D, Bastian BC: MC1R germline variants confer risk for BRAF-mutant melanoma. Science 2006, 313:521-522.

24. Sulem P, Gudbjartsson DF, Stacey SN, Helgason A, Rafnar T, Magnusson KP, Manolescu A, Karason A, Palsson A, Thorleifsson G, Jakobsdottir M, Steinberg S, Palsson S, Jonasson $F$, Sigurgeirsson B, Thorisdottir K, Ragnarsson R, Benediktsdottir KR, Aben KK, Kiemeney LA, Olafsson JH, Gulcher J, Kong A, Thorsteinsdottir, U,Stefansson, K: Genetic determinants of hair, eye and skin pigmentation in Europeans. Nat Genet 2007, 39:1443-1452.

25. Sulem P, Gudbjartsson DF, Stacey SN, Helgason A, Rafnar T, Jakobsdottir M, Steinberg S, Gudjonsson SA, Palsson A, Thorleifsson G, Palsson S, Sigurgeirsson B, Thorisdottir K, Ragnarsson R, Benediktsdottir KR, Aben KK, Vermeulen SH, Goldstein AM, Tucker MA, Kiemeney LA, Olafsson JH, Gulcher 
J, Kong A, Thorsteinsdottir U,Stefansson K: Two newly identified genetic determinants of pigmentation in Europeans. Nat Genet 2008, 40:835-837.

26. Gudbjartsson DF, Sulem P, Stacey SN, Goldstein AM, Rafnar T, Sigurgeirsson B, Benediktsdottir KR, Thorisdottir K, Ragnarsson R, Sveinsdottir SG, Magnusson V, Lindblom A, Kostulas K, Botella-Estrada R, Soriano V, Juberias P, Grasa M, Saez B, Andres R, Scherer D, Rudnai P, Gurzau E, Koppova K, Kiemeney LA, Jakobsdottir $M$, Steinberg $S$, Helgason $A$, Gretarsdottir S, Tucker MA, Mayordomo Jl, et al.: ASIP and TYR pigmentation variants associate with cutaneous melanoma and basal cell carcinoma. Nat Genet 2008, 40: 886-891.

27. Brown KM, Macgregor S, Montgomery GW, Craig DW, Zhao ZZ, Iyadurai K, Henders AK, Homer N, Campbell MJ, Stark M, Thomas S, Schmid H, Holland EA, Gillanders EM, Duffy DL, Maskiell JA, Jetann J, Ferguson M, Stephan DA, Cust AE, Whiteman D, Green A, Olsson H, Puig S, Ghiorzo P, Hansson $\mathrm{J}$, Demenais F, Goldstein AM, Gruis NA, Elder DE, et al.: Common sequence variants on $20 \mathrm{q} 11.22$ confer melanoma susceptibility. Nat Genet 2008, 40:838-840.

28. Bishop DT, Demenais F, lles MM, Harland M, Taylor JC, Corda E, Randerson-Moor J, Aitken JF, Avril MF, Azizi E, Bakker B, Bianchi-Scarra G, Bressac-de Paillerets B, Calista D, CannonAlbright LA, Chin AWT, Debniak T, Galore-Haskel G, Ghiorzo P, Gut I, Hansson J, Hocevar M, Hoiom V, Hopper JL, Ingvar C, Kanetsky PA, Kefford RF, Landi MT, Lang J, Lubinski J, et al.: Genome-wide association study identifies three loci associated with melanoma risk. Nat Genet 2009, 41:920-925.

29. Han J, Kraft $P$, Nan H, Guo Q, Chen C, Qureshi A, Hankinson SE, Hu FB, Duffy DL, Zhao ZZ, Martin NG, Montgomery GW, Hayward NK, Thomas G, Hoover RN, Chanock S, Hunter DJ: A genome-wide association study identifies novel alleles associated with hair color and skin pigmentation. PLOS Genet 2008, 4:e1000074.

30. Kimonis VE, Goldstein AM, Pastakia B, Yang ML, Kase R, DiGiovanna JJ, Bale AE, Bale SJ: Clinical manifestations in 105 persons with nevoid basal cell carcinoma syndrome. Am J Med Genet 1997, 69:299-308.

31. Shanley S, Ratcliffe J, Hockey A, Haan E, Oley C, Ravine D, Martin N, Wicking C, Chenevix-Trench G: Nevoid basal cell carcinoma syndrome: review of $\mathbf{1 1 8}$ affected individuals. Am J Med Genet 1994, 50:282-290.

32. Stacey SN, Gudbjartsson DF, Sulem P, Bergthorsson JT, Kumar R, Thorleifsson G, Sigurdsson A, Jakobsdottir M, Sigurgeirsson $B$, Benediktsdottir KR, Thorisdottir K Ragnarsson R, Scherer D, Rudnai P, Gurzau E, Koppova K, Hoiom V, Botella-Estrada R, Soriano V, Juberias P, Grasa M, Carapeto FJ, Tabuenca P, Gilaberte Y, Gudmundsson J, Thorlacius S, Helgason A, Thorlacius T, Jonasdottir A, Blondal $\mathrm{T}$, et al:: Common variants on $1 \mathrm{p} 36$ and $1 \mathrm{q} 42$ are associated with cutaneous basal cell carcinoma but not with melanoma or pigmentation traits. Nat Genet 2008, 40:13131318.

33. Gandini S, Sera F, Cattaruzza MS, Pasquini P, Abeni D, Boyle $\mathrm{P}$, Melchi CF: Meta-analysis of risk factors for cutaneous melanoma: I. Common and atypical naevi. Eur J Cancer 2005, 41:28-44.

34. MacKie RM, McHenry P, Hole D: Accelerated detection with prospective surveillance for cutaneous malignant melanoma in high-risk groups. Lancet 1993, 341:1618-1620.

35. Falchi M, Spector TD, Perks U, Kato BS, Bataille V: Genomewide search for nevus density shows linkage to two melanoma loci on chromosome 9 and identifies a new QTL on 5q31 in an adult twin cohort. Hum Mol Genet 2006, 15: 2975-2979.

36. Zhu G, Montgomery GW, James MR, Trent JM, Hayward NK, Martin NG, Duffy DL: A genome-wide scan for naevus count: linkage to CDKN2A and to other chromosome regions. Eur J Hum Genet 2007, 15:94-102.

37. Falchi M, Bataille V, Hayward NK, Duffy DL, Bishop JA, Pastinen T, Cervino A, Zhao ZZ, Deloukas P, Soranzo N, Elder DE, Barrett JH, Martin NG, Bishop DT, Montgomery GW, Spector TD: Genome-wide association study identifies variants at 9 p21 and $22 q 13$ associated with development of cutaneous nevi. Nat Genet 2009, 41:915-919.

Published: 27 October 2009

doi:10.1186/gm95

(c) 2009 BioMed Central Ltd 